\title{
The language of exclusion in mental health
}

Sanahuja Muñoz, C; Jiménez Martínez, M; Fdez de Henestrosa Serra, C; Alonso Cecilia, M; Martínez Arambarri, A.

*Hospital Universitario de la Princesa

\section{INTRODUCTION}

Psychiatry in Social Sciences:

There is a link between some social and cultural sciences, such as anthropology and sociology, and mental health, especially in the research area and the conceptualization of mental illness.

The sociologist Talcott Parsons suggests this interaction within the social action framework, which would be determined by the following three contexts: the psychological context, which studies personality through psychology and psychiatry; the social context, determined by the links between individuals and their groups; and the cultural context, given by the rules and values of a certain culture, which is part of the field of work of anthropology.

Society and culture are tightly related concepts, for one does not exist without the other. The first refers to the system of relations that connects individuals creating a functional unit. Culture has more to do with nurture than with nature. It is also a system composed by both intangible (beliefs, ideas and values) and tangible elements: objects, symbols and technologies that represent this cultural content. However, society and culture come together in every individual and this individual, at the same time, is part of the social organization; as a result, there is a reciprocity in psychological and social perspectives, in order to access to the analysis of the phenomenon as a whole. As stated previously, there would be a third system, personality or the psychic system, understood as a set of psychic elements: experiences, character traits, impulses, attitudes etc. The complementarity between society and personality is mediated by the socialization process. Socialization is defined as the process through which people learn and integrate the social and cultural elements of their environment, structuring their personality under the influence of the main social agents, and finally, adapting to their environment.

OBJEIIVES To describe the social and psychological implications derived of the language used by people who live or develop in a context of exclusion within modern societies.

\section{RESULTS}

\section{Symbolic Interactionism:}

The origins of symbolic interactionism can be traced back to the American philosopher, sociologist and psychologist George Herbert Mead (1863-1931). This movement arose from the interest in meaning, symbolic elements and language. Mead suggested that verbal and non verbal communication is full of symbolic elements, thus every social interaction leads to an exchange of symbols. Sociologists and anthropologists who use this approach, focus on "face to face" interactions and the role that this plays in the construction of societies.

\section{"Deviant" behavior: Robert K. Merton}

The sociological explanations focus un the social and cultural aspects linked to deviant behavior. Most of the theories present deviance and crime as the result of structural tension and a lack of moral control within societies.

On the other hand, Robert K. Merton, based on Durkheim's concept of anomie, developed a very influential theory of deviance, identifying five possible reactions to the tension between socially accepted values and means to achieve them, in other words, between accepted rules and reality:

Conformists, who accept both values and conventional means. The majority of the population would be here. innovators, who accept the cultural goals (i.e. the search for success), but reject the conventional means and values. For example criminals who become wealthy.

Ritualists, who accept the rules but have lost the values that sustain them, that is, they follow them mechanically. For example. people whose job is unsatisfying but seeks "being respected".

Isolates, who have abandoned the competitive approach completely, and therefore, have rejected the values and means't maintain it. In general, they are the socially marginalized.

Rebels, who also reject them, but who strive to replace them.

Finally, Merton believes that deviance is the result of the economic gap and the inequality of opportunities. Further researdf such as Albert Cohen also refer to these tensions, but on a collective scale. Cohen mentions that subcultures with inequgit to breed gangs and crime.

Urban Exclusion and Mental Health

The characteristics of the modern urbanization can have negative effects on mental health, due to the influence of $g$ events, such as overpopulation and polluted environments, poverty, dependency on a monetary economy, high and poor social support.

The results of transnational studies (e.g. Brazil, Chile, India, Zimbabwe) have found a twofold increase (approximately) infhe risk of depression in poor people vs. rich people. A correlation between job loss and economic recession and suicide arry hospitalization rates has also been found. Which could mean that the evolution of mental illness could be affected by poverty./

\section{CONCLUSIONS}

In the bibliography we find literature related to linguistic and sociological analyses of the ways in which people in exclusion contexts express themselves in modern intercultural societies. However, there is no research regarding these issues aimed at the clinical practice or focused on expression of symptoms. Therefore, we believe it is necessary to open new research lines aimed at studying the language of exclusion and it's application in everyday clinical practice.

\section{BIBLIOGRAPHY}

(1)Mead, George H.; Morris, Charles W. (1967). Mind, self, and society from the standpoint of a social behaviorist. Chicago London: University of Chicago Press. pp. X78-179.

(2)Rawal, Nabin. Social Inclusion and Exclusion: A Review.

Dhaulagiri Journal of Sociology and Anthropology Vol.2. 161-180.

(3)Merton, Robert, (1964) Teoría y estructura sociales, México, Fondo de Cultura Económica.

(4)Durkheim, Emile (1952 [18971) Suicide, London: Routledge and Kegan Paul. 